\title{
Antibacterial compounds against fish pathogenic bacteria from a combined extract of Angelica gigas and Artemisia iwayomogi and their quantitative analyses
}

\author{
Jae-Woong Lim', Na Young Kim², Jung-Soo Seo ${ }^{4}$, Sung-Hee Jung ${ }^{3}$, So Young Kang ${ }^{1, *}$ \\ ${ }^{1}$ Department of Aqualife Medicine, Chonnam National University, Yeosu 59626, Korea \\ ${ }^{2}$ Pathology Research Division, National Institute of Fisheries Science, Busan 46083, Korea \\ ${ }^{3}$ National Institute of Fisheries Science, Busan 46083, Korea \\ ${ }^{4}$ Aquatic Disease Control Division, National Fishery Products Quality Management Service, Busan 46083, Korea
}

\begin{abstract}
In the search for antibiotic alternatives from safe and effective medicinal plants against fish pathogenic bacteria, we found that a combined extract (CE) of 1:1 (w/w) ratio of Angelica gigas Nakai roots and aerial parts of Artemisia iwayomogi Kitamura showed antibacterial activity against the fish pathogenic bacteria. By antibacterial activity-guided fractionations and isolations, five compounds were isolated and identified as decursinol angelate (1), decursin (2), xanthotoxin (3), demethylsuberosin (4), and 2,4-dihydroxy-6-methoxyacetophenone (5) through spectroscopic analyses, such as nuclear magnetic resonance (NMR) and mass spectrometry (MS). Among the compounds, 1 and 2 showed the highest antibacterial activities against Streptococcus iniae and Vibrio anguillarum, showing minimum inhibitory concentrations (MICs) of $62.5-250 \mu \mathrm{g} / \mathrm{mL}$. Compounds 3, 4, and 5 were also found to be active, with MICs of 31.25-1,000 $\mathrm{mg} / \mathrm{mL}$ for those strains. Furthermore, active compounds, 1 and 2 in CE were simultaneously quantified using high-performance liquid chromatography-tandem MS (HPLC-MS/MS). The average contents of 1 and 2 in CE was 3.68\% and 6.14\%, respectively. The established method showed reliable linearity $\left(r^{2}>0.99\right)$, good precision, accuracy, and specificity with intra- and inter-day variations of $<2 \%$ and recoveries of $90.13 \%-108.57 \%$. These results may be helpful for establishing the chemical profile of $\mathrm{CE}$ for its commercialization as an antibiotic alternative in aquaculture.
\end{abstract}

Keywords: Angelica gigas, Artemisia iwayomogi, decursinol angelate, decursin, fish pathogenic bacteria

Received: Aug 6, 2021 Revised: Sep 15, 2021 Accepted: Sep 27, 2021

${ }^{*}$ Corresponding author: So Young Kang

Department of Aqualife Medicine, Chonnam National University, Yeosu 59626, Korea

Tel: +82-61-659-7176, Fax: +82-61-659-7179, E-mail: sykang1@chonnam.ac.kr

This is an Open Access article distributed under the terms of the Creative Commons Attribution Non-Commercial License (http://creativecommons.org/licenses/by$\mathrm{nc} / 4.0 /$ ) which permits unrestricted non-commercial use, distribution, and reproduction in any medium, provided the original work is properly cited.

Copyright $\odot 2021$ The Korean Society of Fisheries and Aquatic Science 


\section{Introduction}

Fast development of aquaculture and increasing demand for fish have led to intensification of fish farming, magnifying stressors for fish and thus increasing the risk of disease. To date, chemotherapy has been widely used to prevent and treat disease outbreaks (Reverter et al., 2021). However, frequent use of these antibacterial agents causes serious drawbacks, such as environmental contamination, toxicity to the hosts, and even contamination of fish products with drug residues (Kemper, 2008; Koch et al., 2021; Lim et al., 2019), which prompted an urgent need for alternative therapy, including natural products, such as medicinal plants.

In our previous study, we found that Angelica gigas Nakai and Artemisia iwayomogi Kitamura showed the potent anti-bacterial, anti-parasite, anti-fungal and anti-viral activities against various fish pathogens (Jeon et al., 2020). In addition, an ethanolic extract of 1:1 (w/w) ratio of A. gigas and Ar. iwayomogi (thereafter referred to as $\mathrm{CE}$ ) showed strong in vitro and in vivo antibacterial activities against various fish pathogenic bacteria, such as Edwardsiella tarda, Vibrio spp., Photobacterium damselae, Streptococcus spp., and Lactococcus spp. (Seo et al., 2017). A. gigas, commonly known by the Korean name as 'Chamdang-gui', belongs to the Umbelliferae family and is abundantly distributed throughout northern Asia, including Korea (Joo et al., 2010). The roots of this plant have been reported to have various biological activities, such as antifungal (Yoon et al., 2011), antitumor (Lee et al., 2003b), anti-inflammatory (Shin et al., 2009), and neuroprotective (Kang et al., 2005) activities. Coumarins, such as decursinol angelate and decursin, are major components of this plant (Lee et al., 2003a) and they have been reported to have significant antibacterial activities (Lee et al., 2003c; Park et al., 2021).

Ar. iwayomogi, locally known as 'Haninjin' or 'Dowijigi', belongs to the Compositae family and is a perennial herb easily found in Korea (Lee et al., 1993). The aerial part of Ar. iwayomogi has been reported to have antibacterial (Seo et al., 2010), antifungal (Jung et al., 2005), anti-inflammatory (Kim et al., 2005), antitumor (Taleghani et al., 2020), and antioxidative (Sin et al., 2020) activities. Especially, some terpenoids (mono- and sesqui-) in the essential oil (Yu et al., 2003) and some phenolics (Seo et al., 2010) of Ar. iwayomogi are known to have inhibitory effects on bacterial growth.

Botanicals or medicinal plants are known to contain one or many chemical components that may have therapeutic purposes (Heng et al., 2013). Therefore, it is conventional to combine different medicinal plants to achieve various treatment purposes simultaneously or to enhance a single effect without causing severe side effects (Nishiyama et al., 1995). Similarly, combined extract showed extended antimicrobial spectrum, stabilities against heat and $\mathrm{pH}$ treatments (Hsieh et al., 2001), and synergistic antimicrobial effects against oral microorganisms (Rhim et al., 2002). However, since these plant extracts contain various components, standardization through analyses of active marker compounds is required for practical use and will play a central role in the development and modernization of these preparations (Ong, 2004). The chemical standardization of active compounds is of special significance because it directly affects the activity of natural products (Nikam et al., 2012). In addition, plant extracts of consistent quality that contain well-defined components are required for reliable clinical trials and for providing consistent, beneficial therapeutic effects (Mosihuzzaman \& Choudhary, 2008). However, plants contain various compounds and analysis of plant mixtures is not simple owing to their complicated chemical compositions. The analysis procedure includes avoidance of peak interference, selection of maker compounds, modulation for a stable baseline, and specification of a single compound peak (Zhao et al., 2017).

In the present study, considering those requirements, this study aimed to isolate the active markers in CE by antibacterial activity-guided fractionations and to standardize CE using the active markers through high-performance liquid chromatography-tandem mass spectrometry (HPLC-MS/MS). Furthermore, the compounds were investigated for antibacterial activities against S. iniae, V. anguillarum, and E. tarda. To the best of our knowledge, this is the first report on antibacterial activities of these compounds against fish pathogenic bacteria.

\section{Materials and Methods}

\section{Plant materials}

The roots of Angelica gigas Nakai and aerial parts of Artemisia iwayomogi Kitamura were purchased in Kyungdong local market (Seoul, Korea). Both plant materials were identified in our own lab through comparison with reference medicinal plant materials provided by the Ministry of Food and Drug Safety of Korea. The plant materials have been verified by verification method of NHMI (National Herbal Medicine Information, https://nifds. go.kr), and detailed methods and results are described in Supplementary Material, 1. Verification of two medicinal plants. 


\section{Reagents and other materials}

First grade solvents (Daejung Chemicals \& Metals, Siheung, Korea) were used for extraction, fractionation, and isolation. HPLC-grade solvents were purchased from Honeywell B \& J (Morristown, NJ, USA). Sephadex ${ }^{\circledR}$ LH-20 was purchased from GE Healthcare (Chicago, IL, USA). Silica gel column (Si 60) was purchased from Biotage ${ }^{\circledR}$ (Uppsala, Sweden) and commercially prepared TLC plates (Silica gel $60, \mathrm{~F}_{254}$, Merck, NJ, USA) were used. Brain Heart Infusion Agar (BHIA) and Broth (BHIB) were bought from Difco (Becton, NJ, USA).

\section{Extraction and fractionation of $\mathrm{CE}$, and isolation of active compounds}

In order to antibacterial-guided fractionation, dried roots of $A$. gigas and aerial parts of Ar. iwayomogi (670 g as a 1:1 mixture) were finely ground and extracted three times with $50 \%$ ethanol $\left(13.4 \mathrm{~L}\right.$ ) at $40^{\circ} \mathrm{C}$ for $3 \mathrm{~h}$ using ultrasonic apparatus (Powersonic 420, Hwashin Tech., Gwangju-si, Gyeonggi-do, Korea). The extract was then filtered through a Whatman No. 4 filter paper (Maidstone, UK). The 50\% ethanolic extract (CE) was evaporated to dryness under vacuum, yielding $225 \mathrm{~g}$ extract. This extract was then suspended in water and partitioned successively with n-hexane (Hex, $29.7 \mathrm{~g}$ ), methylene chloride (MC, $12.9 \mathrm{~g}$ ), ethyl acetate (EA, $7.7 \mathrm{~g}$ ), water saturated $n$-butanol (W-S Bu, $40.3 \mathrm{~g}$ ) and aqueous (126 g). These fractions were then tested for their antibacterial activity. Since the MC fraction presented the highest antibacterial activities among the five fractions (Table 1), active compounds were isolated from the MC fraction through various chromatographic techniques.

Silica gel chromatography of the MC fraction of CE (12.5 g) with Hex-acetone mixture (84:16 to 0:100) as an eluent afforded six fractions (MC-I to MC-VI). Among the six fractions, MCII (662.9 mg) was subjected to silica gel chromatography with Hex-acetone mixture (84:16 to 0:100) and yielded four sub-fractions (MC-II_fr.1 to 4). MC-II_fr.2 (115.8 mg) was subjected to medium pressure liquid chromatography (MPLC) using silica gel chromatography with chloroform-methanol mixture (99:1 to 0:100), yielding 67 fractions. Among 67 fractions, 36 to 40 fractions were combined to give compound $3(7.5 \mathrm{mg})$. Fractions 52 to $59(88.4 \mathrm{mg})$ were further subjected to Sephadex ${ }^{\circledR}$ LH-20 column chromatography eluted with methanol, yielding 130 fractions. Among 130 fractions, fractions 69 to 77 (15 $\mathrm{mg}$ ) afforded compound $4(9.2 \mathrm{mg})$ through semi-preparative high-performance liquid chromatography (S-4 $\mu \mathrm{m}, 8 \mathrm{~nm}, 250$ $\times 10 \mathrm{~mm}$; J'sphere ODS-H80, YMC, Kyoto, Japan). MC-II_fr.3 and 4 were combined, and the combined fraction $(431.5 \mathrm{mg})$ was subjected to Sephadex ${ }^{\circledR}$ LH-20 column chromatography using methanol-acetone mixture (4:6). Among the resulting 130 fractions, fractions 48 to $65(176.1 \mathrm{mg})$ were subjected to Sephadex ${ }^{\circledR}$ LH-20 column chromatography eluted with methanol, yielding compound 5 (13.2 mg).

\section{Extraction and fractionation of $A$. gigas roots, and isolation of active compounds}

Dried roots of $A$. gigas ( $40 \mathrm{~g}$ ) were extracted four times with methanol $(0.2 \mathrm{~L})$ in an ultrasonic apparatus at $40^{\circ} \mathrm{C}$ for $2 \mathrm{~h}$.

Table 1. MICs of fractions and isolated compounds from CE against fish pathogenic bacteria

\begin{tabular}{llll}
\hline Fractions and compounds & Strains & \\
\cline { 2 - 4 } & S. iniae KCTC3657 $(\mu \mathrm{g} / \mathrm{mL})$ & V. anguillarum KCTC2711 $(\mu \mathrm{g} / \mathrm{mL})$ & E. tarda KCTC12267 $(\mu \mathrm{g} / \mathrm{mL})$ \\
\hline CE & 2,500 & 2,500 & 10,000 \\
MC & 625 & 625 & 2,500 \\
MC-I & 156.25 & 312.5 & 2,500 \\
MC-II & 156.25 & 78.13 & $>10,000$ \\
Decursinol angelate (1) & 62.5 & 62.5 & $>1,000$ \\
Decursin (2) & 250 & 125 & $>1,000$ \\
Xanthotoxin (3) & 1,000 & 31.25 & 1,000 \\
Demethylsuberosin (4) & 125 & $\mathrm{NT}$ & 1,000 \\
2,4-Dihydroxy-6-methoxyacetophenone (5) & 500 & 1,000 & 1,000 \\
AMX & 0.0156 & 0.0312 & 1 \\
OTC & 0.156 & 0.25 & 0.625 \\
\hline
\end{tabular}

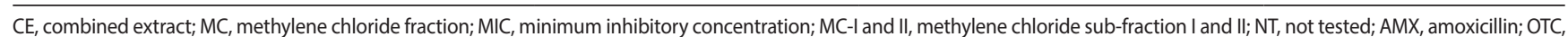
oxytetracycline. 
After solvent removal under reduced pressure, the methanolic extract yielded was $12.1 \mathrm{~g}$. The methanolic extract was suspended in water and partitioned successively with MC. The MC fraction was evaporated to dryness under vacuum and yielded $2.8 \mathrm{~g}$.

Silica gel chromatography by MPLC (Isolera One, Biotage ${ }^{\circledR}$, Uppsala, Sweden) of the MC fraction of $A$. gigas (2.8 g) with a mixture of $n$-hexane (Hex)-acetone (95:5 to 0:100) as an eluent, and afforded four fractions (Fr-I to IV). Fr-II $(81.2 \mathrm{mg}$ ) was subjected to Sephadex ${ }^{\circledR}$ LH-20 column chromatography with methanol and yielded pure compound 1 (44 mg, purity 99.0\%). Fr-III (195.4 mg) was subjected to silica gel chromatography with Hex-MC (50:50 to 0:100) and yielded six sub-fractions (fr-I to fr-VI). Among the six sub-fractions, fr-IV (144.2 mg) was subjected to Sephadex ${ }^{\circledR}$ LH-20 column chromatography with methanol and yielded pure compound 2 (51.2 mg, purity $98.7 \%)$. The purities of standards were over $98 \%$ as determined by HPLC-UV with a wavelength of $210 \mathrm{~nm}$ (Supplementary Material, Fig. S1, tables and figures marked with S are found in the Supplementary Material). All compounds were identified using spectral data, such as HPLC-MS ${ }^{\mathrm{n}}$ fragment pattern (HPLC: Surveyor MS Pump; Autosampler: Surveyor autosampler; MS: ThermoFinnigan LCQ Advantage MAX ion trap mass spectrometer, MA, USA), proton nuclear magnetic resonance $\left({ }^{1} \mathrm{H}-\mathrm{NMR}\right)$, and carbon-13 nuclear magnetic resonance $\left({ }^{13} \mathrm{C}\right.$-NMR) by direct comparison with published data of spectra and structures. NMR spectra (Figs. S2-S6) were recorded in chloroform- $d$, methanol- $d_{4}$, and dimethyl sulfoxide- $d_{6}$ using $400 \mathrm{MHz}$ NMR spectrometer (AVANCE 400 FT-NMR, Bruker, MA, USA). All isolated compounds were screened for antibacterial activity.

\section{Bacterial cultures and antibacterial susceptibility test}

Streptococcus iniae KCTC 3657, Vibrio anguillarum KCTC 2711, and Edwardsiella tarda KCTC 12267 were purchased from Korean Collection for Type Cultures (Daejeon, Korea). For antibacterial susceptibility test using microdilution method (Kang et al., 2008; Langfield et al., 2004), bacterial colonies taken directly from BHIA plates were incubated in BHIB at $28^{\circ} \mathrm{C}$ for 24 h. From this culture, a suspension equivalent to $0.5 \mathrm{McF}$ arland standard in BHIB was prepared.

The fractions or compounds and an equal volume of bacteria at $1 \times 10^{6} \mathrm{CFU} / \mathrm{mL}$ were mixed in a 96-well plate and incubated at $28^{\circ} \mathrm{C}$ for $24 \mathrm{~h}$. The antibiotics amoxicillin and oxytetracycline were used as positive controls. The lowest concentration of antibiotics that visibly inhibited bacterial growth was considered as MIC. Each assay was repeated in three times.

\section{Quantification of active compounds using high-perfor- mance liquid chromatography-tandem mass spectrometry (HPLC-MS/MS) \\ Preparation of standard solutions and samples}

Stock solutions for standard compounds were prepared with HPLC-grade methanol as a solvent. Working calibration solutions were prepared by successive serial dilution of the stock solution with methanol and the final concentrations were 5, 25, $50,100,500$, and $1,000 \mathrm{ng} / \mathrm{mL}$ for compound 1 , and 5, 25, 250, 1,000 , and 2,000 ng/mL for compound 2 .

Dried CE was dissolved in 50\% methanol to prepare $1 \mathrm{mg} /$ $\mathrm{mL}$ stock solution. The stock solution of $\mathrm{CE}$ was diluted to make working solutions at concentrations of 1,3 , and $10 \mu \mathrm{g} / \mathrm{mL}$.

\section{High-performance liquid chromatography-tandem mass spec- trometry (HPLC-MS/MS) conditions}

Agilent Technologies 1260 liquid chromatograph coupled to a 6460-triple quadrupole mass spectrometer equipped with an electrospray ionization (ESI) ion source was used for quantitative and qualitative analyses. Optimized conditions were as follows: drying nitrogen gas flow, $10 \mathrm{~L} / \mathrm{min}$; nebulizer pressure, 35 psi. drying gas temperature, $350^{\circ} \mathrm{C}$; capillary voltage, 5,000 volts; flow rate, $0.6 \mathrm{~mL} / \mathrm{min}$; scan range, $50-500(\mathrm{~m} / \mathrm{z})$. The analytical column was a Capcell Pak $\mathrm{C}_{18} \mathrm{MG}(250 \times 4.6 \mathrm{~mm}, 5 \mu \mathrm{m}$; Shiseido, Tokyo, Japan) connected to a short pre-column. The column was operated at $30^{\circ} \mathrm{C}$. Table $\mathrm{S} 1$ summarizes the retention times, specific transitions, and collision energies used for each compound and solvent condition.

\section{Method validation}

For linearity study, calibration plots were constructed using diluted stock solutions of a series of at least five concentrations, by plotting mean integrated chromatographic peak area against the corresponding concentration. , limit of detection (LOD) and limit of quantitation (LOQ) were calculated in accordance with the International Conference on Harmonization (ICH) Q2B Guideline. Method precision was validated through determination of intra- and inter-day variances. Recovery was used to further evaluate the accuracy of the method. Known amounts of standard solutions were mixed with known amounts of samples. Next, the resultant samples were analyzed, and triplicate experiments were performed at each level. Average recoveries were estimated by the following formula: Recovery $(\%)=$ (amount 
found - original amount) / amount spiked $\times 100 \%$, and RSD (relative standard deviation, \% $=($ standard deviation $/$ mean $) \times$ $100 \%$. RSD was taken as a measure of precision and accuracy. Specificity was achieved by analyzing MRM signals. All peaks of the target compounds in CE were identified by comparison of retention time, as well as parent and product ions with standards in MRM spectra.

\section{Statistical analysis}

Based on the standard deviation of the response $(\sigma)$ and the slope (S) from calibration curve using Microsoft Excel, LOD and LOQ were calculated by following equations: $\mathrm{LOD}=3.3 \times$ $\sigma / \mathrm{S}$ and $\mathrm{LOQ}=\mathrm{LOD} \times 3$.

\section{Results and Discussion}

\section{Antibacterial activities against fish pathogenic bacteria of fractions from CE and their identification analyses using high performance liquid chromatography (HPLC)-ion trap MS}

To isolate the compounds responsible for the antibacterial activity of $\mathrm{CE}$ as active markers, an activity-guided fractionation strategy was performed throughout the separation procedure. The MC fraction of CE showed the strongest antibacterial activity against $S$. iniae and $V$. anguillarum (Table 1). Activity-guided fractionation of the active $\mathrm{MC}$ fraction yielded the sub-fractions MC-I and MC-II, which showed strong antibacterial activity against S. iniae and $V$. anguillarum with MIC values of 156.25 $\mu \mathrm{g} / \mathrm{mL}$ and 78.13 to $312.5 \mu \mathrm{g} / \mathrm{mL}$, respectively (Table 1 ). The major compounds of the most active sub-fractions (MC-I and II) were identified through LC-ion trap MS (Analytical conditions are in Supplementary Material, 2. Analytical conditions of LC-ion trap MS). LC-MSn analysis suggested that major compounds with the same characteristics as those of decursinol angelate (1) and decursin (2) were present in MC-I (Fig. 1 and Figs. S7-S9), and 1, 2, xanthotoxin (3), and 2,4-dihydroxy-6-methoxyacetophenone (5) were present in MC-II (Figs. S10-S13). Because 1 and 2 were identified as major compounds of the active fractions MC-I and II, they were separated from roots of A. gigas for massive and efficient isolation of two compounds. After isolation, 1 and 2 were identified as decursinol angelate and decursin, respectively, by analyses of the spectral data using ${ }^{1} \mathrm{H}-\mathrm{NMR}$ (Yoo et al., 2008) and ESI-MS ([M+H $]^{+}$ at $m / z$ 329). In addition, three compounds were isolated from MC-II. Compounds 3, 4, and 5 were identified as xanthotoxin (Muller et al., 2004), demethylsuberosin (Masuda et al., 1998), and 2,4-dihydroxy-6-methoxyacetophenone (Brown, 1992), respectively, based on ${ }^{1} \mathrm{H}-\mathrm{NMR}$ and ESI-MS data $\left([\mathrm{M}+\mathrm{H}]^{+}\right.$at $\mathrm{m} /$ $z 217$ of $3,[\mathrm{M}+\mathrm{H}]^{+}$at $m / z 231$ of 4 and $[\mathrm{M}-\mathrm{H}]^{-}$at $m / z 181$ of 5). Of the five compounds, 1-4 are representative compounds reported in Angelica species, and 5 is reported to be present in Artemisia species. In the present study, only one of the compounds derived from Ar. iwayomogi was isolated in the active fractions. Essential oils of Ar. iwayomogi are known to have inhibitory effects on bacterial growth (Cha, 2007), and these essential oils are obtained by extraction with a highly polar solvent or distillation (Cha, 2007; Choi et al., 2017). Therefore, one of possible explanations for failure to isolate these essential oils with antibacterial activity is that essential oils are highly volatile, whereas $\mathrm{CE}$ was extracted with low-polarity solvents. This phenomenon coincided with a previous report that recovery of essential oils from plants is low at ethanol concentrations below 55\% (Durling et al., 2007).

\section{Antibacterial activities of antibacterial compounds against fish pathogenic bacteria}

The five compounds were investigated for antibacterial activities against $S$. iniae, $V$. anguillarum, and E. tarda (Table 1). To the best of our knowledge, this is the first report on antibacterial activities of these five compounds against fish pathogenic bacteria. The isolated compounds showed MIC values of 31.25 to $1,000 \mu \mathrm{g} / \mathrm{mL}$, and compounds 1-4 showed strong antibacterial activities against the test strains. In contrast, compound 5 was less active $(500-1,000 \mu \mathrm{g} / \mathrm{mL})$ than the other compounds. The positive controls amoxicillin and oxytetracycline showed MIC ranges of 0.0156 to $1 \mu \mathrm{g} / \mathrm{mL}$ and 0.156 to $0.625 \mu \mathrm{g} / \mathrm{mL}$ against the test strains, respectively. Similar susceptibilities of several terrestrial bacteria to the isolated compounds have been reported in other studies. According to previous studies (Lee et al., 2003c; Taechowisan et al., 2013), 2 exhibited antibacterial activity against Bacillus subtilis with MIC values of 12.5 and $64 \mu \mathrm{g} /$ $\mathrm{mL}$, and 1 has an MIC of $50 \mu \mathrm{g} / \mathrm{mL}$. In addition, 1 and 2 possess strong antibacterial activities with MIC values of $6-200 \mu \mathrm{g} / \mathrm{mL}$ against Helicobater pylori (Bae et al., 1998). Compound 3 had MICs at a range of 500-2,000 $\mu \mathrm{g} / \mathrm{mL}$ against various gram-positive and -negative strains (de Souza et al., 2005). Compound 5 at $800 \mu \mathrm{g} / \mathrm{mL}$ has previously been shown to exert a slight inhibitory activity against Clostridium perfringens (Ivarsen et al., 2014). This evidence suggest that major compounds of $\mathrm{CE}$ possess antibacterial activities against both gram-negative and -positive bacteria. In the present study, among the five com- 

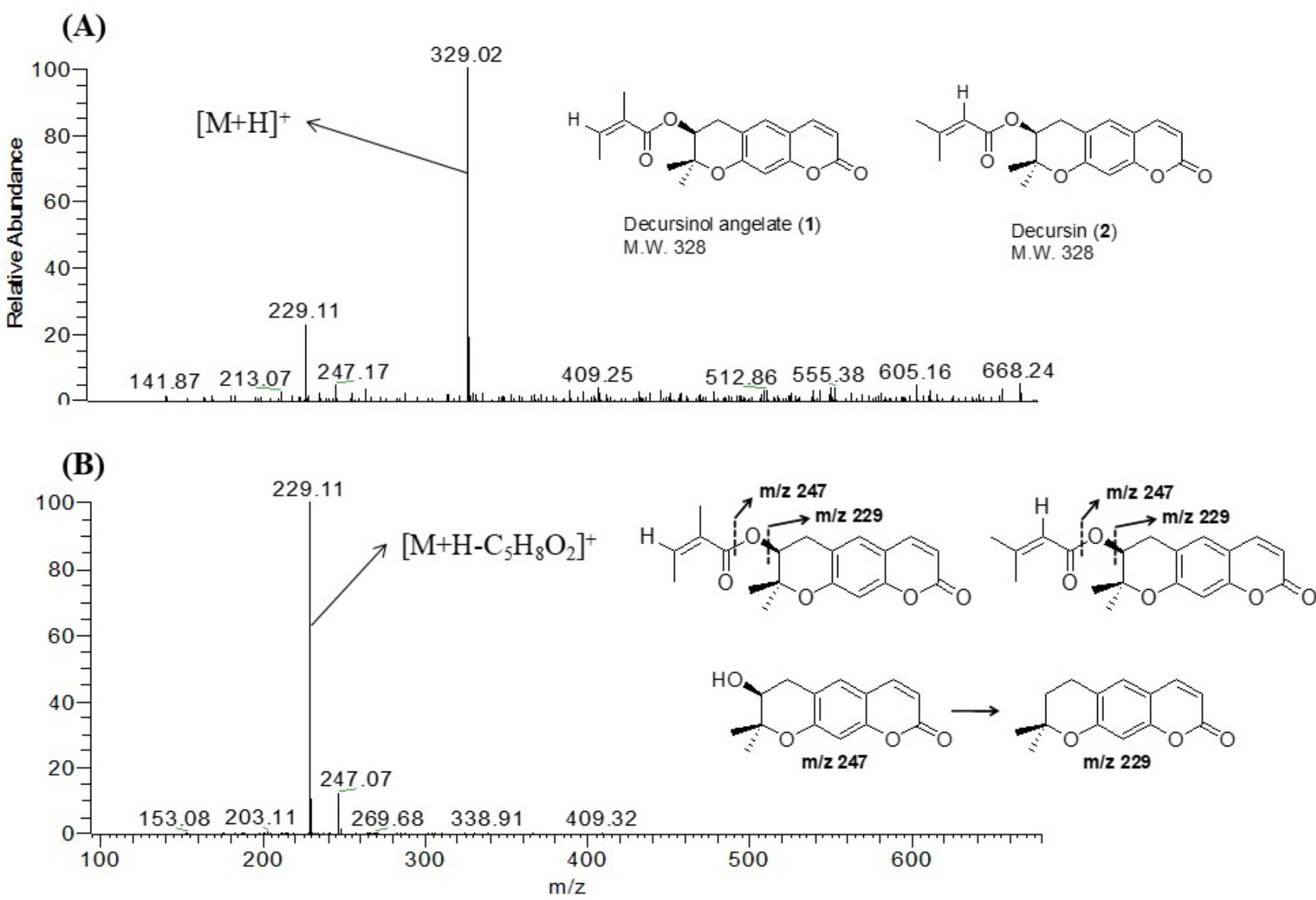

Fig. 1. Mass spectra and fragmentation patterns of the active compounds in CE. (A) ESI (positive) mass spectra of active compounds. (B) MS/MS fragmentation patterns of active compounds. CE, combined extract.

pounds, 1 and 2 showed the most potent, broad-spectrum activities against $S$. iniae ( 62.5 and $250 \mu \mathrm{g} / \mathrm{mL}$, respectively) and $V$. anguillarum ( 62.5 and $125 \mu \mathrm{g} / \mathrm{mL}$, respectively). For this reason, 1 and 2 were selected as active marker compounds of $\mathrm{CE}$ and then quantified by HPLC-MS/MS.

\section{Quantification of active marker compounds in CE}

A. gigas contains dihydropyranocoumarins, 1 and 2 as major compounds, and these compounds are structural isomers having the same formula (Fig. 2). To separate, detect, and quantify these two peaks, LC-UV methods using buffer elution have been reported (Ahn et al., 2008; Kim et al., 2009; Lee et al., 2003a). However, considering the complicated chemical composition of combined plant extracts, HPLC-MS/MS method may have advantages. Although previous studies performed quantification using HPLC-MS/MS (Park et al., 2013), direct comparisons between their and our results are inappropriate because they did not separate the two peaks. Recently, one study has reported separation of 1 and 2 by LC-MS/MS using columns of various sizes, but it was not possible to separate two isomeric peaks with a single column (Kim et al., 2018). In the present study, three different $C_{18}$ columns $(50,150$, and $250 \times 4.6$ $\mathrm{mm}$ ) were tested for the separation of 1 and 2. Among them, $250 \times 4.6 \mathrm{~mm}$ column showed to be the most suitable and it provided good peak separation (Fig. 3). In contrast, other column showed poor peak separations at the same condition (Fig. S14). Therefore, 1 and 2 were quantified under optimized LC conditions using $250 \times 4.6 \mathrm{~mm}$ column.

Method validation included tests of linearity, precision, accuracy, and specificity. Calibration curves for HPLC-MS/MS analyses were linear over a concentration range of 5 to 1,000 $\mathrm{ng} / \mathrm{mL}$ (regression line: $\mathrm{y}=395.39 \mathrm{x}-193.52$ with a correlation 
<smiles>C/C=C(/C)C(=O)O[C@H]1Cc2cc3ccc(=O)oc3cc2O[C@H]1C</smiles>

Decursinol angelate (1)<smiles>CC(C)=CC(=O)O[C@H]1Cc2cc3ccc(=O)oc3cc2O[C@@H]1C</smiles>

Decursin (2)<smiles>CC(C)=CCc1cc2ccc(=O)oc2cc1O</smiles>

Demethylsuberosin (4)

Xanthotoxin (3)<smiles>COc1cc(O)cc(O)c1C(C)=O</smiles>

\section{2,4-Dihydroxy-6-methoxyacetophenone (5)}

Fig. 2. Chemical structures of the compounds isolated from Angelica gigas and Artemisia iwayomogi.

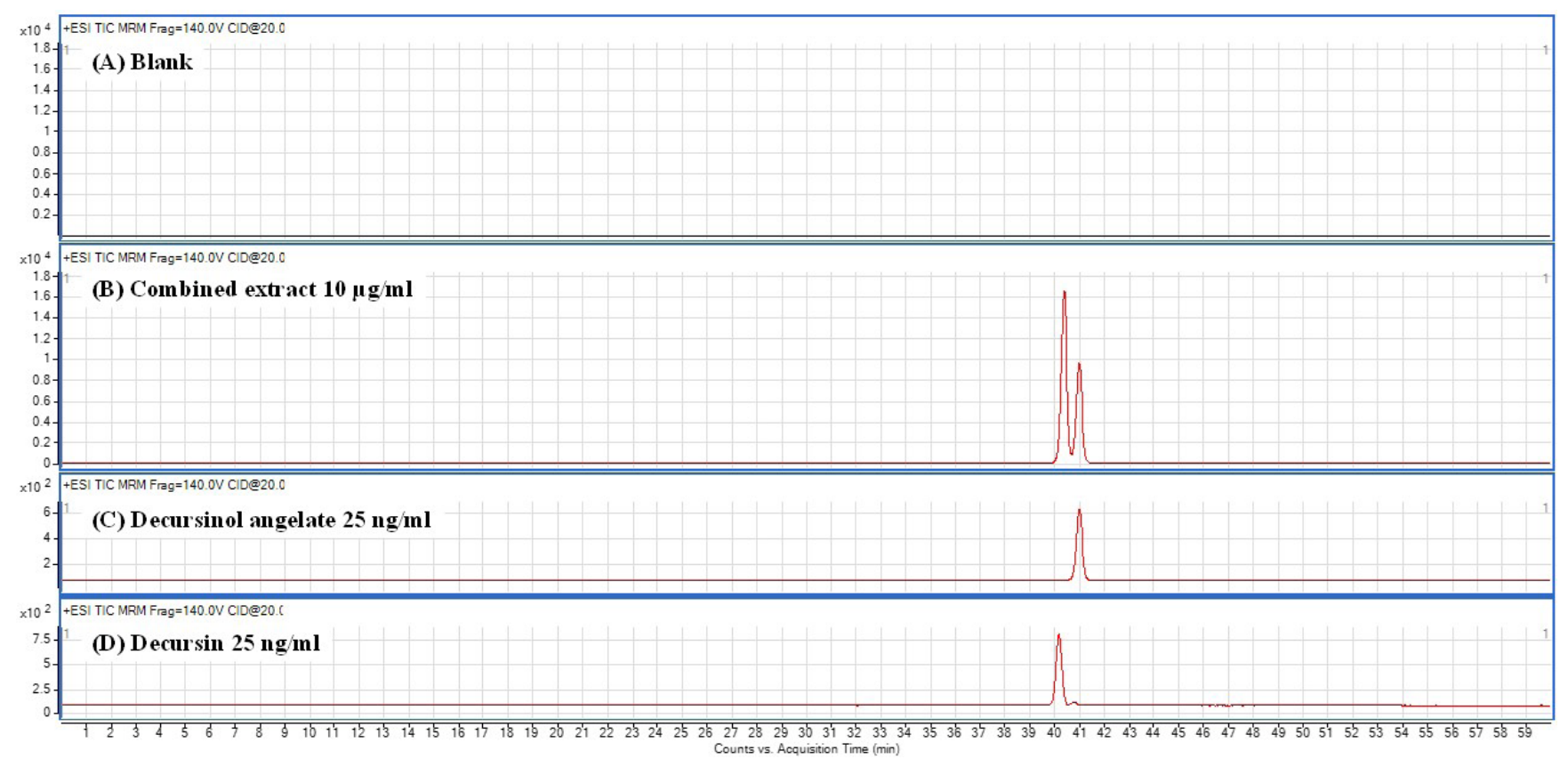

Fig. 3. Representative MRM chromatograms of CE and its active compounds. (A) Chromatogram of blank solution. (B) Chromatogram of the active compounds in CE. (C) and (D) Chromatograms of standard compounds. CE, combined extract. 
coefficient $r^{2}$ of 0.9999 ) for 1 , and 5 to $2,000 \mathrm{ng} / \mathrm{mL}$ (regression line: $y=370.47 x-606.95$ with a correlation coefficient $r^{2}$ of 0.9999 ) for 2 . On the basis of the calibration curves, LOD and LOQ were calculated to be 0.72 and $2.18 \mathrm{ng} / \mathrm{mL}$ for 1 , and 1.85 and $5.63 \mathrm{ng} / \mathrm{mL}$ for 2 , respectively (Table 2 ).

Method reproducibility was evaluated by intra- $(n=3)$ and inter-day $(n=9)$ variability in three replicate analyses of sample solutions. Relative standard deviation (RSD) was less than $2 \%$, showing good precision (Table 3 ).

The recoveries of 1 and 2 were assessed by spiking samples with high, medium, and low concentrations of each compounds $(20,100$, and 800 ppb for $1 ; 30,200$, and $1,333 \mathrm{ppb}$ for 2$)$. Average recoveries ranged from $90.13 \%$ to $108.57 \%$ (Table 4 ). All the peaks of 1 and 2 in CE were identified by comparison of retention time, as well as parent and product ions with those of standards in MRM spectra. As a result, high specificity was shown (Fig. S15). Therefore, this method showed suitable precision, accuracy, reproducibility, and specificity.

Content analysis of 1 and 2 in CE was performed by HPLCMS/MS (Fig. 1). Average contents of 1 and 2 were calculated to be $3.68 \pm 0.07 \%$ and $6.14 \pm 0.04 \%$, respectively (Table 5). Considering the MICs $(62.5$ and $250 \mu \mathrm{g} / \mathrm{mL})$ and contents of the two active compounds (sum of the two compounds: $9.82 \%$ ), the antibacterial activity of CE with an MIC of 2,500 $\mu \mathrm{g} / \mathrm{mL}$ can be explained.

\section{Conclusions}

In the present study, five compounds were isolated from a combined extract of 1:1 (w/w) ratio of the roots of $A$. gigas and aerial parts of Ar. iwayomogi. The antibacterial activities of these isolated compounds against S. iniae, V. anguillarum, and E. tarda were reported for the first time, and among these compounds, 1 and 2 showed strong activities against $S$. iniae and $V$.

Table 2. Retention time, linear regression equation, correlation coefficient $\left(r^{2}\right)$, linear range, LOD, and LOQ of active compounds

\begin{tabular}{lllllll}
\hline Compounds & Retention time & Regression equation & $r^{2}$ & Linear range $(\mathrm{ng} / \mathrm{mL})$ & $\mathrm{LOD}(\mathrm{ng} / \mathrm{mL})$ & $\mathrm{LOQ}(\mathrm{ng} / \mathrm{mL})$ \\
\hline Decursinol angelate (1) & 40.982 & $\mathrm{y}=395.39 x-193.52$ & 0.9999 & $5-1,000$ & 0.72 & 2.18 \\
Decursin (2) & 40.154 & $\mathrm{y}=370.47 x-606.95$ & 0.9999 & $5-2,000$ & 1.85 & 5.63 \\
\hline
\end{tabular}

LOD, limit of detection; LOQ, limit of quantification.

Table 3. Intra- and inter-day precisions of active compounds

\begin{tabular}{|c|c|c|c|c|}
\hline \multirow[t]{3}{*}{ Combined extract $(\mu \mathrm{g} / \mathrm{mL})$} & \multicolumn{4}{|l|}{ Precision: RSD (\%) } \\
\hline & \multicolumn{2}{|c|}{ Decursinol angelate (1) } & \multicolumn{2}{|l|}{ Decursin (2) } \\
\hline & Intra-day $(n=3)$ & Inter-day $(\mathrm{n}=9)$ & Intra-day $(\mathrm{n}=3)$ & Inter-day $(\mathrm{n}=9)$ \\
\hline 1 & 0.34 & 1.07 & 0.52 & 0.28 \\
\hline 3 & 0.09 & 0.25 & 0.24 & 0.40 \\
\hline 10 & 0.09 & 0.22 & 0.10 & 0.03 \\
\hline
\end{tabular}

$\mathrm{RSD}$, relative standard deviation.

Table 4. Accuracy data of active compounds

\begin{tabular}{|c|c|c|c|c|c|}
\hline Compounds & Original (ng/mL) & Spiked (ng/mL) & Detected (ng/mL) & Recovery (\%) & RSD (\%) \\
\hline \multirow[t]{3}{*}{ Decursinol angelate (1) } & 186.54 & 20 & 208.25 & 108.57 & 0.35 \\
\hline & & 100 & 283.15 & 96.61 & 0.33 \\
\hline & & 800 & 984.85 & 99.78 & 0.07 \\
\hline \multirow[t]{3}{*}{ Decursin (2) } & 308.78 & 30 & 335.82 & 90.13 & 2.31 \\
\hline & & 200 & 511.73 & 101.47 & 0.33 \\
\hline & & 1,333 & $1,639.06$ & 99.79 & 0.03 \\
\hline
\end{tabular}

RSD, relative standard deviation; The original is the compound concentration corresponding to $5 \mathrm{ppm}$ of combined extract. 
Table 5. Contents of active compounds in CE

\begin{tabular}{|c|c|c|c|c|c|c|}
\hline \multirow[t]{2}{*}{ Combined extract $(\mu \mathrm{g} / \mathrm{mL})$} & \multicolumn{3}{|c|}{ Decursinol angelate (1) } & \multicolumn{3}{|c|}{ Decursin (2) } \\
\hline & mean (\%) & SD & RSD (\%) & Mean (\%) & SD & RSD (\%) \\
\hline 1 & 3.58 & 0.04 & 1.08 & 6.17 & 0.02 & 0.28 \\
\hline 3 & 3.72 & 0.01 & 0.25 & 6.09 & 0.02 & 0.40 \\
\hline 10 & 3.75 & 0.01 & 0.23 & 6.16 & 0.00 & 0.03 \\
\hline Average & 3.68 & 0.07 & 2.02 & 6.14 & 0.04 & 0.59 \\
\hline
\end{tabular}

$\mathrm{CE}$, combined extract; RSD, relative standard deviation.

anguillarum. An HPLC-MS/MS method was successfully developed for the simultaneous quantification for 1 and 2 as active compounds. Taken together, these results may be helpful for establishing the chemical profile of $\mathrm{CE}$ for commercialization as an antibiotic alternative in aquaculture. In addition, this study will be helpful for quantitative analysis of 1 and 2 as well as standardization of extract using A. gigas.

\section{Supplementary Materials}

Supplementary materials are only available online from: https:// doi.org/10.47853/FAS.2021.e31.

\section{Competing interests}

No potential conflict of interest relevant to this article was reported.

\section{Funding sources}

This research was supported by a grant from the National Institute of Fisheries Science, Korea (R2021067).

\section{Acknowledgements}

Not applicable.

\section{Availability of data and materials}

Upon reasonable request, the datasets of this study can be available from the corresponding author.

\section{Ethics approval and consent to participate}

This article does not require IRB/IACUC approval because there are no human and animal participants.

\section{ORCID}

Jae-Woong Lim

https://orcid.org/0000-0001-9092-7376

Na Young Kim
Jung-Soo Seo

Sung-Hee Jung

So Young Kang

\section{References}

Ahn MJ, Lee MK, Kim YC, Sung SH. The simultaneous determination of coumarins in Angelica gigas root by high performance liquid chromatography-diode array detector coupled with electrospray ionization/mass spectrometry. J Pharm Biomed Anal. 2008;46:258-66.

Bae EA, Han MJ, Kim NJ, Kim DH. Anti-Helicobacter pylori activity of herbal medicines. Biol Pharm Bull. 1998;21:990-2.

Brown GD. Two new compounds from Artemisia annua. J Nat Prod. 1992;55:1756-60.

Cha JD. Chemical composition and antibacterial activity against oral bacteria by the essential oil of Artemisia iwayomogi. J Bacteriol Virol. 2007;37:129-36.

Choi JS, Song BM, Park HJ. Identification of the component with anti-acetylcholinesterase activity from the essential oil of $A r$ temisia iwayomogi. Korean J Plant Resour. 2017;30:17-21.

de Souza SM, Delle Monache F, Smânia A Jr. Antibacterial activity of coumarins. Z Naturforsch C. 2005;60:693-700.

Durling NE, Catchpole OJ, Grey JB, Webby RF, Mitchell KA, Foo LY, et al. Extraction of phenolics and essential oil from dried sage (Salvia officinalis) using ethanol-water mixtures. Food Chem. 2007;101:1417-24.

Heng MY, Tan SN, Yong JWH, Ong ES. Emerging green technologies for the chemical standardization of botanicals and herbal preparations. Trends Anal Chem. 2013;50:1-10.

Hsieh PC, Mau JL, Huang SH. Antimicrobial effect of various combinations of plant extracts. Food Microbiol. 2001;18:35-43.

Ivarsen E, Fretté XC, Christensen KB, Christensen LP, Engberg RM, Grevsen K, et al. Bioassay-guided chromatographic isolation and identification of antibacterial compounds 
from Artemisia annua L. that inhibit Clostridium perfringens growth. J AOAC Int. 2014;97:1282-90.

Jeon EJ, Lee NS, Seo JS, Jung SH, Kim MS, Kang SY, et al. Study of anti-pathogenic herbal materials for the eco-friendly drugs in aquaculture. J Fish Mar Sci Edu. 2020;32:980-7.

Joo SS, Park D, Shin S, Jeon JH, Kim TK, Choi YJ, et al. Anti-allergic effects and mechanisms of action of the ethanolic extract of Angelica gigas in dinitrofluorobenzene-induced inflammation models. Environ Toxicol Pharmacol. 2010;30:127-33.

Jung HS, Cha MK, Kwon YJ, So JS. Differential inhibitory effect of Artemisia extract between Staphylococcus aureus and vaginal Lactobacillus spp. Korean Soc Biotechnol Bioeng J. 2005;20:228-32.

Kang SY, Kang JY, Kim SY, Kim DH, Oh MJ. Antimicrobial activities of alkyl gallates alone and in combination with antibiotics against the fish pathogenic bacteria Edwardsiella tarda and Vibrio anguillarum. Korean J Fish Aquat Sci. 2008;41:188-92.

Kang SY, Lee KY, Sung SH, Kim YC. Four new neuroprotective dihydropyranocoumarins from Angelica gigas. J Nat Prod. 2005;68:56-9.

Kemper N. Veterinary antibiotics in the aquatic and terrestrial environment. Ecol Indic. 2008;8:1-13.

Kim KM, Jung JY, Hwang SW, Kim MJ, Kang JS. Isolation and purification of decursin and decursinol angelate in Angelica gigas Nakai. J Korean Soc Food Sci Nutr. 2009;38:653-6.

Kim SH, Choi CH, Kim SY, Eun JS, Shin TY. Anti-allergic effects of Artemisia iwayomogi on mast cell-mediated allergy model. Exp Biol Med. 2005;230:82-8.

Kim SJ, Ko SM, Choi EJ, Ham SH, Kwon YD, Lee YB, et al. Simultaneous determination of decursin, decursinol angelate, nodakenin, and decursinol of Angelica gigas Nakai in human plasma by UHPLC-MS/MS: application to pharmacokinetic study. Molecules. 2018;23:1019.

Koch N, Islam NF, Sonowal S, Prasad R, Sarma H. Environmental antibiotics and resistance genes as emerging contaminants: methods of detection and bioremediation. Curr Res Microb Sci. 2021;2:100027.

Langfield RD, Scarano FJ, Heitzman ME, Kondo M, Hammond GB, Neto CC. Use of a modified microplate bioassay method to investigate antibacterial activity in the Peruvian medicinal plant Peperomia galioides. J Ethnopharmacol. 2004;94:279-81.

Lee JH, Chae HJ, Kim DH, Lee SH, Park SY, Kang YG. HPLC analysis and extraction methods of Decursin and Decursinol angelate in Angelica gigas roots. Korean J Pharmacogn. 2003a;34:201-205.

Lee KR, Zee OP, Kwak JH, Kim YS, Park HK, Koo KA, et al. The polysaccharide fraction of Artemisia species(I). Korean J Pharmacogn. 1993;24:289-95.

Lee S, Lee YS, Jung SH, Shin KH, Kim BK, Kang SS. Anti-tumor activities of decursinol angelate and decursin from Angelica gigas. Arch Pharm Res. 2003b;26:727-30.

Lee S, Shin DS, Kim JS, Oh KB, Kang SS. Antibacterial coumarins from Angelica gigas roots. Arch Pharm Res. 2003c;26:449-52.

Lim JW, Shin SM, Jung SJ, Lee MK, Kang SY. Optimization of antibacterial extract from lacquer tree (Rhus verniciflua Stokes) using response surface methodology and its efficacy in controlling edwardsiellosis of olive flounder (Paralichthys olivaceus). Aquaculture. 2019;502:40-7.

Masuda T, Takasugi M, Anetai M. Psoralen and other linear furanocoumarins as phytoalexins in Glehnia littoralis. Phytochemistry. 1998;47:13-6.

Mosihuzzaman M, Choudhary MI. Protocols on safety, efficacy, standardization, and documentation of herbal medicine. Pure Appl Chem. 2008;80:2195-230.

Muller M, Byres M, Jaspars M, Kumarasamy Y, Middleton M, Nahar L, et al. 2D NMR spectroscopic analyses of archangelicin from the seeds of Angelica archangelica. Acta Pharm. 2004;54:277-85.

Nikam PH, Kareparamban J, Jadhav A, Kadam V. Future trends in standardization of herbal drugs. J Appl Pharm Sci. 2012;2:38-44.

Nishiyama N, Wang YL, Saito H. Beneficial effects of S-113m, a novel herbal prescription, on learning impairment model in mice. Biol Pharm Bull. 1995;18:1498-1503.

Ong ES. Extraction methods and chemical standardization of botanicals and herbal preparations. J Chromatogr B. 2004;812:23-33.

Park KY, Lee AY, Ban JH, Park JK, Lee EH. Effects of herbal medicine on breastfeeding - analysis of marker substances in Saenghwa-tang by HPLC and LC/MS/MS. J Korean Obstet Gynecol. 2013;26:48-65.

Park SI, Heo SH, Lee J, Shin MS. Extraction of active compounds from Angelica gigas using supercritical carbon dioxide and its physiological activity. J Converg Inf Technol. 2021;11:206-12.

Reverter M, Tapissier-Bontemps N, Sarter S, Sasal P, Caruso D. Moving towards more sustainable aquaculture practices: 
a meta-analysis on the potential of plant-enriched diets to improve fish growth, immunity and disease resistance. Rev Aquac. 2021;13:537-55.

Rhim JY, Moon YS, Jung SH, Lee KY, Lyu SY, Shim CS, et al. Antimicrobial activities of combined extract of Aloe vera with propolis against oral pathogens. J Korean Soc Food Sci Nutr. 2002;31:899-904.

Seo JS, Kim NY, Jeong SH, Kim MS, Hwang JY, Kang SY, et al. Anti-bacterial composition for comprising extract of mixed herbal medication. Korea patent 10-1709169. 2017 Feb 16.

Seo KS, Jeong HJ, Yun KW. Antimicrobial activity and chemical components of two plants, Artemisia capillaris and Artemisia iwayomogi, used as Korean herbal Injin. J Ecol Environ. 2010;33:141-7.

Shin S, Jeon JH, Park D, Jang JY, Joo SS, Hwang BY, et al. Anti-inflammatory effects of an ethanol extract of Angelica gigas in a carrageenan-air pouch inflammation model. Exp Anim. 2009;58:431-6.

Sin SM, Jeong WM, Kil YS, Lee DY, Kim SG, Goo YM. Anti-inflammatory and anti-bacterial activities of Artemisia iwayomogi Kitamura extract fractions. J Life Sci. 2020;30:40-4.

Taechowisan T, Chanaphat S, Ruensamran W, Phutdhawong WS. Antibacterial activity of decursin from Streptomyces sp. GMT-8; an endophyte in Zingiber officinale Rosc. J Appl Pharm Sci. 2013;3:74-8.

Taleghani A, Emami SA, Tayarani-Najaran Z. Artemisia: a promising plant for the treatment of cancer. Bioorg Med Chem. 2020;28:115180.

Yoo JS, Ahn EM, Song MC, Bang MH, Kim DH, Han MW, et al. Quantitative analysis of coumarins from Angelica gigas using ${ }^{1} H$-NMR. Food Sci Biotechnol. 2008;17:573-7.

Yoon MY, Kim YS, Ryu SY, Choi GJ, Choi YH, Jang KS, et al. In vitro and in vivo antifungal activities of decursin and decursinol angelate isolated from Angelica gigas against Magnaporthe oryzae, the causal agent of rice blast. Pestic Biochem Physiol. 2011;101:118-24.

Yu HH, Kim YH, Kil BS, Kim KJ, Jeong SI, You YO. Chemical composition and antibacterial activity of essential oil of Artemisia iwayomogi. Planta Med. 2003;69:1159-62.

Zhao Y, Li HX, Kim YH, Cho CW, Hwang SY, Oh HA, et al. Standardization of extract mixture of Chaenomeles sinensis and Phyllostachys bambusoides for anti-obesity by HPLCUV. Arch Pharm Res. 2017;40:1156-65. 